\title{
THE RADIOCARBON RECORD IN TREE RINGS OF THE LAST 8000 YEARS
}

\author{
HANS E SUESS \\ Department of Chemistry, University of California, San Diego, \\ La Jolla, California 92093
}

ABSTRACT. It has become generally accepted during the last year that ${ }^{14} \mathrm{C}$ fluctuations, the so-called "wiggles", observed in wood, dated by its tree rings, do indeed exist. Furthermore the La Jolla measurements show that apart from experimental noise, they do not represent random red noise, but characteristic, recurring features. In 1971, Houtermans found indications for the existence of cyclic components and recent Fourier analyses of all the available data by Neftel and Hartwig show a 200-year component. Cyclic oscillations with other periods appear to be present during limited time intervals. The character of the oscillations is not harmonic. The time derivative of many fluctuations is remarkably constant and such that the ${ }^{14} \mathrm{C}$ rises by 1 percent in about 20 years and decreases by 1 percent in slightly more than twice that length of time. The properties of the overall radiocarbon record have to be considered in attempts to explain the variations in terms of variations of the cosmic ray-production rate and changes of the geochemical distribution of radiocarbon.

\section{INTRODUCTION}

Annual tree rings can, in many ways, provide information on past environmental conditions. The rate of growth of trees, and, thus, the width of the annual rings in their wood, greatly depends on local climatic conditions, primarily on temperature and precipitation. The stable isotopes ${ }^{18} \mathrm{O}$ and $\mathrm{D}$ in wood largely reflect the isotopic composition of the metabolized water at the time of growth. Also, the ${ }^{13} \mathrm{C} /{ }^{12} \mathrm{C}$-ratio in wood depends on local factors at the time of growth. The only quantity which can be expected to be largely independent of the geographic location is the radiocarbon content, the ${ }^{14} \mathrm{C} /{ }^{12} \mathrm{C}$ ratio of the carbon in the wood. This quantity corresponds closely to that of the ambient air, if one corrects for isotope fractionation by normalizing to a fixed ${ }^{13} \mathrm{C} /{ }^{12} \mathrm{C}$-ratio.

At the 12th Nobel Symposium held at Uppsala University in August 1969 I had presented evidence showing that the ${ }^{14} \mathrm{C} /{ }^{12} \mathrm{C}$-ratio fluctuated throughout the time for which dendrochronologically dated wood was available, that is, for a time more than 7000 years into the past. These fluctuations give rise to the so-called "wiggles" in the radiocarbon calibration curve. During the past ten years, the question of the validity of these wiggles was extensively discussed in the literature (see Damon, Lerman, and Long, 1978). As a consequence of the existence of these wiggles, the uncertainties of the calibrated dates, for certain time ranges, were much larger than those of the original measurements. The amplitude of the ${ }^{14} \mathrm{C}$ variations causing the wiggles, however, appeared to be smaller than the limits of error of many laboratories. Therefore, for a long time, the opinion was frequently expressed that the wiggles were experimental and that the relationship between measured ${ }^{14} \mathrm{C}$ concentrations and true calendar ages was best illustrated by a smooth curve, that could be approximated by a sine wave with an amplitude of about 10 percent and a period of about 10,000 years.

In 1969 I remarked, during the discussion of my curve (Suess 1971, p 310): "The line was not drawn by computer-I drew the line by 'cosmic 
schwung'. There is nothing final about many of those wiggles. I wanted to indicate the character of the curve which we can expect to obtain with more data. For certain time-ranges, there is no proof of the existence of rapid wiggles, although they probably exist there, as well as in other time-ranges in which we can recognize them with certainty."

Since then about three times the number of samples on which the Uppsala curve was based have been measured in La Jolla. Answers to the following questions, considered doubtful by many workers only a year ago, can now be given with certainty:

1) To what extent are the ${ }^{14} \mathrm{C}$ fluctuations as represented by wiggles in the calibration curve statistically justified and to what extent may they be caused by experimental errors?

2) Are the observed ${ }^{14} \mathrm{C}$ fluctuations truly independent of geographic location?

3) Do the observed fluctuations represent a random noise or do they contain a structure with typical features and periodically recurring components?

In order to investigate the character of the secular ${ }^{14} \mathrm{C}$ variations and their possible correlations with other geophysical parameters, a large number of accurate ${ }^{14} \mathrm{C}$ determinations are necessary. The accuracy of the measurements is limited by the time one can spend on each measurement and by the amount of carbon available from each sample. In order to obtain an overview of the past fluctuations, a compromise had to be therefore made between the number of determinations and their accuracy. We have selected the precision of our measurements in such a way that a maximum number of measurements could be obtained with still sufficient precision to be informative. A standard counting error of $\pm 4 \%$ o was obtained for most determinations of near-recent activity. Had we carried out our determinations with twice this accuracy, we would have obtained only one quarter of the number of results. This paper describes the general properties of the ${ }^{14} \mathrm{C}$ fluctuations during the time for which wood dated by its tree rings was available, which is approximately from about $6000 \mathrm{BC}$ to the present. The dendrochronological dates were based almost entirely on the Bristlecone Pine chronology of C W Ferguson, from which we had obtained almost all the investigated wood samples. Values from the Becker floating chronologies D-8, D-7/9/12, and M-5 were also used. Nearly all the values have been published previously (Suess, 1978). Unfortunately, the $\mathrm{D}-3 / 10$ series gives inconsistent results and some dendrochronological revisions will be necessary. The overview given in this paper describes the most prominent features of the ${ }^{14} \mathrm{C}$ variations. The recent very accurate and detailed investigations of specific, limited, time periods, as carried out in Groningen (de Jong and Mook, 1979), in Seattle (Stuiver, 1978), in Belfast (Pearson and others, in press), and in Heidelberg (Bruns, pers commun) are not considered here.

\section{Data analyses}

In figures 1 and 3 the differences between experimentally determined ${ }^{14} \mathrm{C}$ values and those of a sine function with a period of 12,100 years and 
an amplitude of $105 \%$ are plotted against the dendrochronologically determined sample age. The experimental values published previously (Suess, 1978) differ from the values used here by a constant $6 \%$, because of a change in normalization of the standard to 0.95 percent NBS oxalic acid.

The lines shown in the figures are computer drawn spline functions. Their smoothing factors were chosen in such a way that features that appeared significant remained nearly unchanged even though much of the experimental noise was necessarily retained.

To investigate the properties of time series of the type shown in figure 1, Fourier analyses are carried out and power spectra are derived. Hartwig Kruse, Max-Planck-Institut für Chemie, Mainz, has done this using spline functions of varying degrees of smoothing. In all cases in which the whole time range was used the existence of a significant 203 \pm 3 year period was found (fig 2). This period was particularly pronounced during the early times until about $3300 \mathrm{BC}$ and during the most recent time since about $1000 \mathrm{BC}$, but was nearly absent during the intermediate period. Albrecht Neftel, Physikalisches Institut, Universität Bern, has further investigated frequency spectra and phase relationships in $\Delta^{14} \mathrm{C}$ functions for various time intervals ( $\mathrm{Neftel}, \mathrm{ms}$ in preparation). All these investigations have confirmed, in a rigorous and irrefutable way, my previous suspicion that the ${ }^{14} \mathrm{C}$ variations are not random fluctuations. This suspicion led me to spend many years on these experimental observations because of the fundamental consequences of such a conclusion. The non-randomness of the fluctuations shows that they cannot be experimental artifacts, but that they constitute a new geophysical parameter that illustrates, in an as yet unexplored way, secular variations of the factors that determine the atmospheric ${ }^{14} \mathrm{C}$ activity of atmospheric carbon dioxide. That this new geophysical parameter pertains indeed to the planet Earth as a whole, follows from the fact that the atmosphere mixes within less than 2 years, a time short compared to residence time and decay constant of ${ }^{14} \mathrm{C}$. This has been shown by studies of nuclear fallout and interhemispheric mixing of bomb ${ }^{14} \mathrm{C}$. However, a small dependence of the ${ }^{14} \mathrm{C}$ level on geographic location cannot be excluded. Lerman, Mook, and Vogel (1970) have found that ${ }^{14} \mathrm{C}$ in wood from the southern

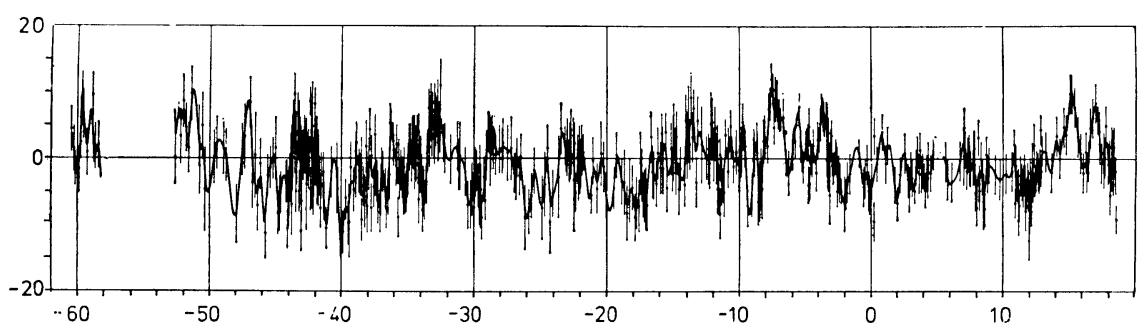

Fig 1. Variations of the atmospheric ${ }^{14} \mathrm{C}$ level during the past 8000 years as derived from La Jolla ${ }^{14} \mathrm{C}$ measurements (calculated with a ${ }^{14} \mathrm{C}$ half-life of 5730 years). Error bars denote standard counting error of each measurement. The line through the data points is a computer drawn spline function. 
hemisphere seems systematically about 4\%o lower than in the northern hemisphere. Cain and Suess (1976) give an upper limit for the difference between North American bristlecone pine wood and that of European oak of $3 \%$. However, an error of 29 years in the European oak chronology was found (Becker, pers commun) indicating that this limit is considerably smaller.

\section{Trends and features}

It is not necessary to carry out rigorous mathematical analyses of the data to be able to recognize a certain nonrandomness in the global ${ }^{14} \mathrm{C}$ record. It can now be seen easily by a careful scrutiny of figure 3 . The 200-year period indicated in the power spectrum does not appear to be the only periodic phenomenon in the time dependence of atmospheric ${ }^{14} \mathrm{C}$. The peaks in the power spectrum around 500, 1000, and 2000 years, are not as such statistically significant, as had been pointed out by Houtermans (1971), but certain peculiar features that can be discerned in figure 3 may be taken as indications for the existence of such additional regularities. There appears to be a tendency of a ${ }^{14} \mathrm{C}$ maximum during the second half of each millennium. At the beginning of a millennium there is usually an indication of a ${ }^{14} \mathrm{C}$ minimum. The ${ }^{14} \mathrm{C}$ level almost always rises faster than it declines. The existence of such regularities was suspected in 1969 and was used as a guide in drawing the first calibration curve. Comparison with the new computer drawn calibration curve

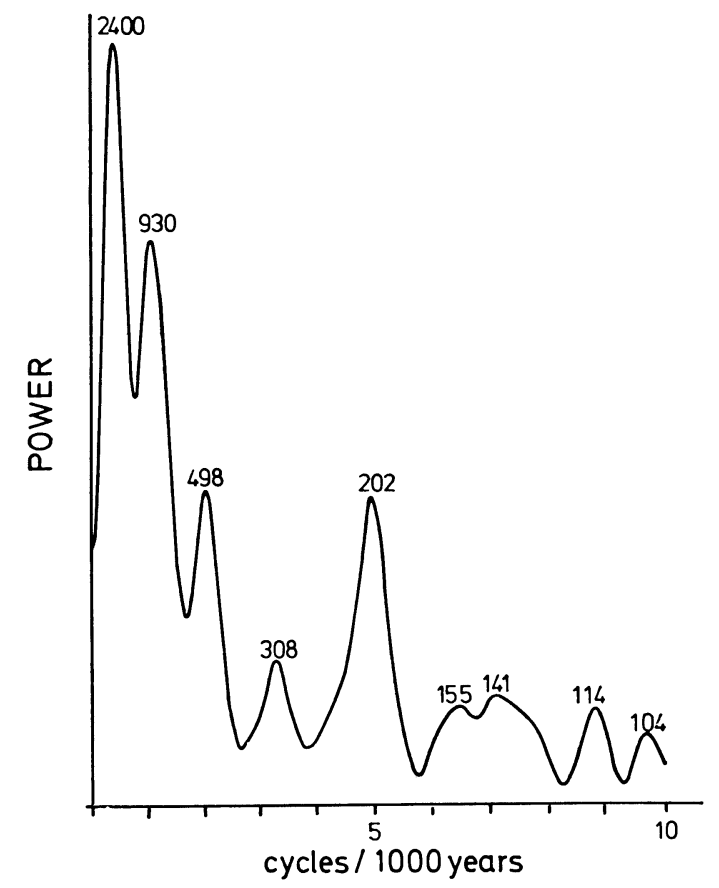

Fig 2. Typical Fourier spectrum of a $\Delta^{14} \mathrm{C}$ function as shown in figure 1. 


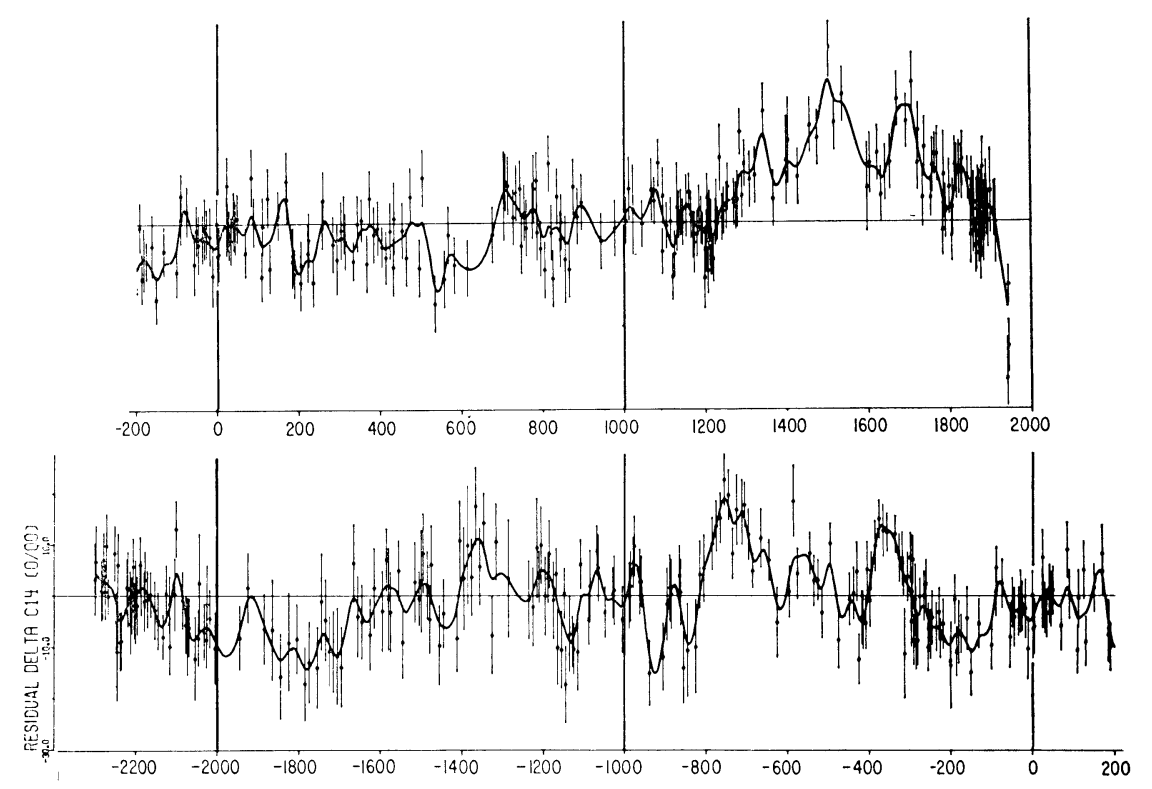

A.

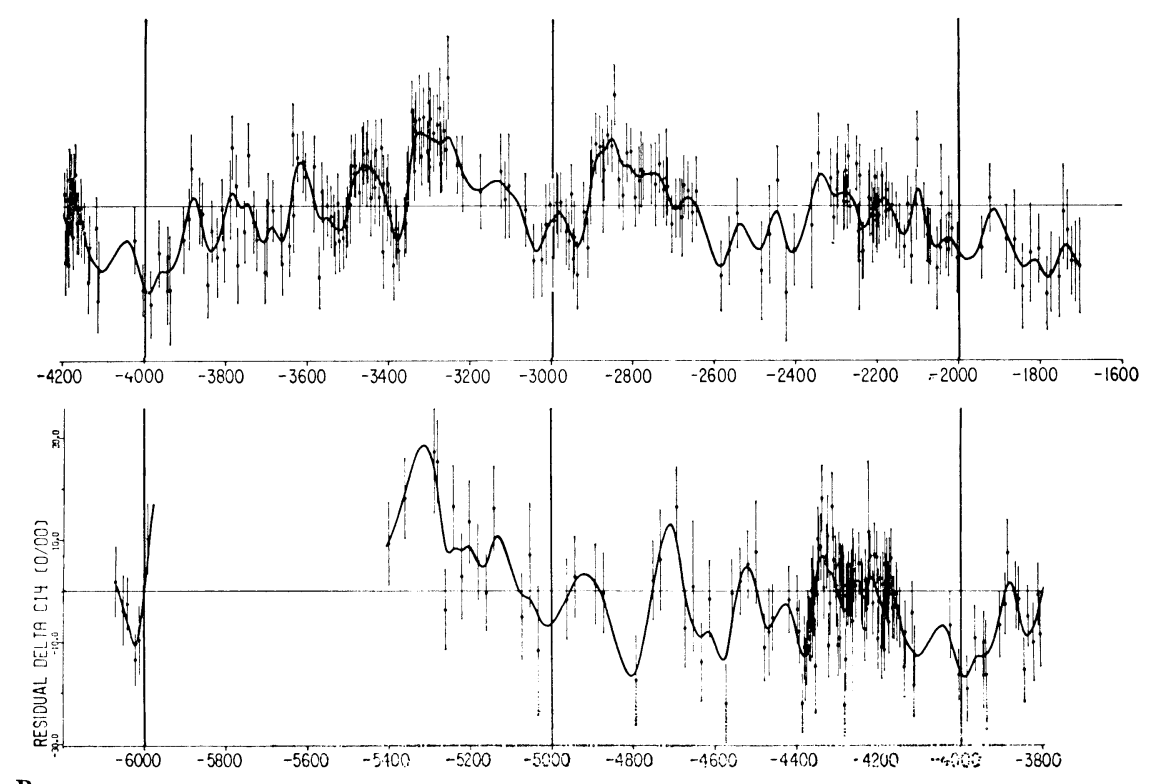

Fig 3. Same as figure 1, but with the time axis expanded to show details for 2000year sections with recurring features discernible. 
(Suess, 1979) shows to what extent the regularities had been correctly anticipated. A rise of the ${ }^{14} \mathrm{C} /{ }^{12} \mathrm{C}$ value by one percent normally takes about 20 years; the decrease by one percent following such a rise takes slightly more than twice as long. The decrease following a maximum levels off exponentially over a period of more than a hundred years.

The picture derived from the La Jolla measurements (fig 3) is discussed here going into the past in consecutive one thousand year intervals. It shows the following details:

Second millennium AD: The two maxima around AD 1500 and 1700 were first observed by DeVries in 1956 and have been remeasured with great precision by Stuiver (1978), using samples from trees grown in the Northwestern United States near the Pacific coastline. Numerical data are not yet available, but Stuiver states that his new measurements confirm quantitatively and in an impressive way the correlation of ${ }^{14} \mathrm{C}$ values with solar activity throughout the time for which sun spot data are available. This includes the time of the well known Spörrer and Maunder sun-spot minima in the 15th and 17th centuries (Eddy, 1977). The new measurements by Stuiver do not change the character of the overall picture for this century as shown in figure 3 .

First millennium AD: Bristlecone pine values for this millennium are incomplete, but samples dated by a European oak chronology based on the work of Becker and of Holstein are now available. M Bruns at the University of Heidelberg, is presently concentrating on measurements of samples from this period. His measurements indicate the existence of pronounced fluctuations (pers commun). They are not shown in figure 3.

First millennium BC: Very pronounced oscillations occurred during this time. Their largest amplitudes occurred around 300 and 700 BC. Whether or not these two oscillations correlate with climatic events, just as the two maxima during the current millennium correlate with the little ice age in Europe, cannot yet be answered with certainty. It is possible that the so-called "Grenz-horizons" of central Europe indicate climatic changes of unusual severity during this period.

Second millennium BC: The ${ }^{14} \mathrm{C}$ level during the time from $2000 \mathrm{BC}$ to 1000 вС appears to have been relatively quiet. Probably the only significant maximum was reached during this millennium in the 14th century BC. More measurements for this period are needed and samples from a floating Becker chronology will be used for additional measurements in La Jolla.

Third millennium BC: This period appears to have been exceptionally quiet, as accurate measurements for a floating chronology from this time showed almost no ${ }^{14} \mathrm{C}$ fluctuations at all (Pearson and others, 1977). There is no doubt, however, that a typical ${ }^{14} \mathrm{C}$ rise occurred at the beginning of the third millennium in the 29th century BC (Mook, Munant, and Waterbolk, 1972). Unfortunately, the La Jolla bristlecone pine measurements for the time from 2650 to $2300 \mathrm{BC}$ are incomplete and samples from a Becker chronology D-3/12 do not lead to a consistent picture. 
Fourth millennium BC: Because of the impressive ${ }^{14} \mathrm{C}$ oscillations that occurred during this time, the time interval from 3700 to $3300 \mathrm{BC}$ has been carefully studied. In La Jolla, an adequate number of bristlecone pine samples and also samples of the Becker D-7 floating chronology were measured (Suess and Becker, 1977). More recently, a large number of samples from the Becker D-7 chronology were also measured in Groningen with an unusually high precision of 1.5\% (de Jong and Mook, 1979). When normalized to the same standard, the three series of measurements agree within statistical expectations. The measurements allow us to set the lower limit for the difference between California bristlecone pine wood and that of European oak at less than two per mil. Within this limit the oscillations on the two continents have identical amplitudes and are perfectly synchronous.

Fifth millennium BC: A very large number of samples from the floating Becker chronology D-8 were measured in La Jolla. The results show a typically rapid ${ }^{14} \mathrm{C}$ rise around $4420 \mathrm{BC}$ and the usual slower decrease following it. Unfortunately, the number of bristlecone pine samples measured for this millennium is relatively small and the absolute date for the D-8 chronology, may, therefore, be uncertain by more than 20 years. Furthermore, an earlier maximum around $5700 \mathrm{BC}$ seems to have occurred during this millennium.

Sixth millennium $\mathrm{BC}$ : Our knowledge of the ${ }^{14} \mathrm{C}$ fluctuations during this millennium is still very incomplete, because of a gap in the bristlecone pine sequence of samples that $\mathrm{C}$ W Ferguson could make available for ${ }^{14} \mathrm{C}$ determinations. This gap covered the time from 5900 to $5300 \mathrm{BC}$. Floating chronologies from this time range have been established by Becker, but unfortunately we have not found these series to overlap significantly the period for which ${ }^{14} \mathrm{C}$ determinations on bristlecone pine samples had been possible. C W Ferguson, however, has made available, for ${ }^{14} \mathrm{C}$ determinations, seven absolutely dated bristlecone pine samples from around 6000 BC. Their measurements indicate a ${ }^{14} \mathrm{C}$ minimum at their time range. The samples have now been found by Ferguson to be about 30 years older than originally assumed. Therefore, they belong to the 7 th millennium $\mathrm{BC}$ and indicate ${ }^{14} \mathrm{C}$ minimum close to the end of this millennium (Ferguson, Gimbutas, and Suess, 1976).

Seventh millennium and before: Unfortunately, it is not yet possible to answer the important question whether ${ }^{14} \mathrm{C}$ was rising or dropping during this and previous millennia.

Becker has worked out two relatively long floating chronologies for the 7 th and part of the 8th millennia Bc. Samples from these chronologies already have been measured in La Jolla as well as in two other laboratories. However, these chronologies do not overlap with periods for which the ${ }^{14} \mathrm{C}$ level is known from bristlecone pine measurements and it is, therefore, not possible to assign an absolute date to these floating chronologies. 


\section{Causes and interpretations}

The ultimate aim is to find the causes of the secular ${ }^{14} \mathrm{C}$ variations. They must be either changes in the production rate of ${ }^{14} \mathrm{C}$ in the terrestrial atmosphere or changes in the geochemical distribution of the carbon on the surface of the earth. Both causes must prevail, but the question is, which predominates. The fact that the ${ }^{14} \mathrm{C}$ variations of the past 300 years correlate with solar activity as well as with climate has been emphasized previously and has now been newly established in a most convincing manner by Stuiver (1978). Whatever might cause changes in the ${ }^{14} \mathrm{C}$ level of the atmospheric $\mathrm{CO}_{2}$ might well have an influence upon the global climate.

Houtermans (1966) was the first who calculated relationships between production rate and atmospheric ${ }^{14} \mathrm{C}$ level for plausible geochemical models, and also the relationship between geochemical distribution and the atmospheric ${ }^{14} \mathrm{C}$ level. The atmosphere-ocean system acts as a low pass filter that attenuates the amplitudes of variations in the production rate in such a way that rapid variations in the production rate affect the ${ }^{14} \mathrm{C}$ level to a much smaller degree than slow, gradual changes. Similarly, the functional dependence of the ${ }^{14} \mathrm{C}$ level upon changes in reservoir sizes and transfer rates of carbon on the surface of the earth can be described. In this way, theoretical expectations can be compared with experimental results, so that noises and signals can be separated and clues for the causes of the ${ }^{14} \mathrm{C}$ variations can be found. This will be attempted in a future paper.

Arguments indicating that changes in the ${ }^{14} \mathrm{C}$ production rate through solar modulation of the galactic cosmic ray flux is the main cause of the ${ }^{14} \mathrm{C}$ variations are: 1) the correlation of ${ }^{14} \mathrm{C}$ level and sunspot numbers during the past 300 years, 2) the regularity with which certain features appear periodically in the time sequence of the ${ }^{14} \mathrm{C}$ variations, eg, the phase angle of the 200-year period (Neftel, $\mathrm{ms}$ in preparation), 3) the more rapid rise than decline of secular ${ }^{14} \mathrm{C}$ levels. Favoring the oceans as the major factor producing ${ }^{14} \mathrm{C}$ fluctuations appear to be: 1) the rate of ${ }^{14} \mathrm{C}$ rise occasionally seems greater than what is expected from heliomagnetic modulation of cosmic rays, 2) the amplitudes of ${ }^{14} \mathrm{C}$ variations appear to be independent of the geomagnetic dipole moment, and 3) from the viewpoint of conventional meteorology a correlation of global climate with the ${ }^{14} \mathrm{C}$ level, if substantiated, would be easier to understand if the oceans and not the sun were its cause.

In any case, it seems probable now that the carbon-14 record in tree rings will be most valuable for an understanding of global climatic variations on the century timescale. The most conclusive evidence could be derived from a tree-ring sequence going back to the last stages of the great ice ages. Hopefully, such a tree-ring sequence will be available within a few more years and, by then, the world's radiocarbon laboratories will be in a position to make optimal use of this valuable source of information. 


\section{ACKNOWLEDGMENTS}

For more than 10 years nearly half the capacity of the La Jolla Radiocarbon Laboratory was devoted to measurements of ${ }^{14} \mathrm{C}$ in wood of known age. During this time, the staff members of the laboratory, in particular Carol Hutto and Timothy Linick have carried out the technical operation with unusual patience, skill and enthusiasm. I wish to express my warmest thanks for their dedication to this difficult and sometimes monotonous work. C W Ferguson supplied the valuable bristlecone pine samples and B Becker provided most samples from European oaks.

A generous award from the Alexander von Humboldt Foundation made it possible for me to discuss the most recent experimental results with colleagues in Europe. Thanks are also due to Professors Münnich and Wagener for the hospitality at their institutes.

The National Science Foundation through its Geochemistry program Grant no. EAR76-22623 and predecessor grants has financed this and other projects pursued by the La Jolla Radiocarbon Laboratory. The NSF Atmospheric Sciences Section has also financially contributed to the success of this work.

\section{REFERENCES}

Cain, W F and Suess, H E, 1976, Carbon-14 in tree-rings: Jour Geophys Research, v 81, p 3688-3694.

Damon, P E, Lerman, J C, and Long, A, 1978, Temporal fluctuations of atmospheric ${ }^{14} \mathrm{C}$, causal factors and implications: Ann Rev Earth and Planetary Sci, v 6, p 457 494.

Eddy, J A, 1977, The case of the missing sunspots: Sci Am, v 236, p 80-82.

Ferguson, C W, Gimbutas, M, and Suess, H E, 1976, Historical dates for Neolithic sites of southeast Europe: Science, v 191, p 1170-1172.

Houtermans, I C, 1966, On the quantitative relationship between geophysical parameters and the natural carbon-14 inventory: Zeitschr Physik, v 193, p 1-12. 1971. Geophysical interpretations of bristlecone pine radiocarbon measurements using a method of Fourier analysis of unequally spaced data: PhD thesis, Univ Bern.

de Jong, A F M and Mook, W G, 1979, Confirmation of the Suess wiggles, 3200-3700 BC: Nature, v 280, p 40-41.

Lerman, J C, Mook, W G, and Vogel, J C, 1970, C-14 in tree rings from different locations, in Olsson, I U, ed, Radiocarbon variations and absolute chronology, Nobel symposium, 12th Uppsala 1969, Proc: Stockholm, Almqvist \& Wiksell-Gebers Forlag AB, p 275-301.

Mook, W G, Munant, A V, and Waterbolk, H T, 1972, Determination of age and duration of stratified prehistoric bog settlements, in Rafter, $\mathbf{T}$ A and Grant-Taylor, $\mathbf{T}$, eds, Internatl radiocarbon conf, 8th, Proc: Wellington, New Zealand, Royal Soc New Zealand.

Pearson, G W, Pilcher, J R, Baillie, M G L, and Hillam, J, 1977, Absolute radiocarbon dating using a low altitude European tree-ring calibration: Nature, v 270, p 25-28.

Stuiver, Minze, 1978, Radiocarbon timescale tested against magnetic and other dating methods: Nature, v 273, p 271-274. 
Suess, H E, 1971, Bristlecone pine calibration of the radiocarbon time scale 5300 BC to the present, in Olsson, I U, ed, Radiocarbon variations and absolute chronology, Nobel symposium, 12th Uppsala 1969, Proc: Stockholm, Almqvist and WiksellGebers Forlag AB, p 303-313.

1971, The three causes of the secular carbon-14 fluctuations, their amplitudes and time constants, in Olsson, I U, ed, Radiocarbon variations and absolute chronology, Nobel symposium, 12th Uppsala 1969, Proc: Stockholm, Almqvist and Wiksell-Gebers Forlag AB, p 595-605.

1979 , The ${ }^{14} \mathrm{C}$ level during the fourth and second half of the fifth millennium ${ }_{B C}$ and the ${ }^{14} \mathrm{C}$ calibration curve, in Berger, Rainer and Suess, H E, eds, Radiocarbon dating, Internatl conf on radiocarbon dating, 9th, Los Angeles and La Jolla, June 1976, Proc: Berkeley/Los Angeles, Univ California Press, p 538-544. 1979, A calibration table for conventional radiocarbon dates, in Berger, Rainer and Suess, H E, eds, Radiocarbon dating, Internatl conf on radiocarbon dating, 9th, Los Angeles and La Jolla, June 1976, Proc: Berkeley/Los Angeles, Univ California Press, p 777-784.

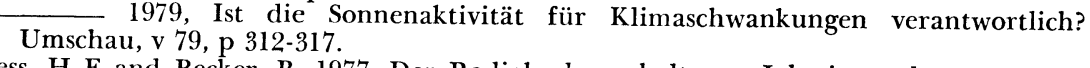

Suess, H E and Becker, B, 1977, Der Radiokarbongehalt von Jahrringproben aus postglazialen Eichenstämmen Südmitteleuropas, in Frenzel B, ed, Erdwissenschaftliche Forschung, Bd 13, Dendrochronologie und postglaziale Klimaschwankungen, Mainz, June 1974, Proc: Wiesbaden, Steiner Varlag.

\section{DISCUSSION}

Barbetti: It seems almost fashionable to attribute rapid ${ }^{14} \mathrm{C}$ changes to solar activity. I would like to point out that there is some evidence for rapid geomagnetic variations; they might also have produced ${ }^{14} \mathrm{C}$ variations similar to those you see in the tree-ring record.

Suess: Indeed, I should have said that ${ }^{14} \mathrm{C}$ changes are due to changes in the ${ }^{14} \mathrm{C}$ production rate, which can be caused by many different factors. Heliomagnetic modulation is one of them, geomagnetic variation might be another one. Variations in the galactic cosmic flux could be another, but, of course, nothing is known about such variations.

Fritz: How many of these very detailed studies on ${ }^{14} \mathrm{C}$ variations in time are paralleled by ${ }^{18} \mathrm{O}$ and ${ }^{2} \mathrm{H}$ analyses on wood. Such analyses might have paleoclimatic significance and could, thus, contribute to discussions on the carbon cycle.

Suess: Certainly. There are a number of investigators engaged in ${ }^{18} \mathrm{O}$ and $\mathrm{D}$ measurements in wood from periods during which major ${ }^{14} \mathrm{C}$ fluctuations occur. To my knowledge none of these investigations has been concluded. 